\title{
Challenging Incommensurability: What We Can Learn from Ludwik Fleck for the Analysis of Configurational Innovation
}

\author{
Alexander Peine \\ Published online: 2 November 2011 \\ (C) The Author(s) 2011. This article is published with open access at Springerlink.com
}

\begin{abstract}
This paper argues that Ludwik Fleck's concepts of thought collectives and proto-ideas are surprisingly topical to tackle some conceptual challenges in analyzing contemporary innovation. The objective of this paper is twofold: First, it strives to establish Ludwik Fleck as an important classic on the map of innovation analysis. A systematic comparison with Thomas Kuhn's work on paradigms, a concept highly influential in various branches of innovation studies, suggests a number of pronounced yet under-researched advantages of a Fleckian perspective in the context of technological change and innovation. Secondly, the paper links these advantages to some recent changes in the organization of innovation. Due to the rising pervasiveness of Information and Communication Technologies (ICTs), configurational innovation has become commonplace that cuts across the boundaries of established trajectories of knowledge generation. Fleck's graded understanding of the closedness of thought collectives and his weak notion of incommensurability provide powerful metaphors to grasp the peculiarities of configurational innovation.
\end{abstract}

Keywords Thought style $\cdot$ Paradigm $\cdot$ Ludwik Fleck ·

Configurational technology $\cdot$ Innovation

\section{Introduction}

In this paper, I revisit Ludwik Fleck's work on thought styles and thought collectives. In Science and Technology Studies (STS), Fleck is well-known for his "protoconstructivist theory" (Smith 2000) that has early anticipated many of the pivotal tenets of a contemporary understanding of science. With regard to

\footnotetext{
A. Peine $(\bowtie)$

Innovation Studies, Copernicus Institute of Sustainable Development, Utrecht University, P.O. Box 80115, 3508 TC Utrecht, The Netherlands

e-mail: a.peine@uu.nl
} 
understanding technological change and innovation, however, he has thus far received only little and also unsystematic attention. This is especially unfortunate given Thomas Kuhn's extensive influence in innovation studies. While Kuhn has introduced many of his central ideas with explicit reference to Fleck, marked differences exist between the works of these scholars. In this paper, I discuss these differences, propose a Fleckian perspective on technological change and innovation and demonstrate how this perspective can enrich our understanding of contemporary innovation. In a nutshell, therefore, this paper strives to establish Ludwik Fleck as an important classic on the map of innovation scholars.

In innovation studies, it has long been claimed that technological change should be conceived as a patterned process of knowledge creation. In this regard, notions such as technological paradigms (Dosi 1982; Granberg and Stankiewicz 1981; Johnston 1972), trajectories (Nelson and Winter 1977) or frames (Bijker 1987; Kaplan and Tripsas 2008) have borrowed from Kuhnian ideas about scientific progress. I argue that, useful as these concepts are, they suffer from a strong interpretation of Kuhn's notion of incommensurability, and, consequently, from what could be called artifact centrism. Due to this heritage, they are unable to grasp innovation processes that cut across the boundaries of established patterns of technological change. Fleck's framework seems to be much more suitable, as it entertains a weak notion of incommensurability. I shall demonstrate that this makes a Fleckian imagery an excellent basis to understand innovation of complex and systemic technologies and some of the organizational challenges around such technologies.

The paper is organized as follows. "Kuhn and Fleck: a comparison" briefly summarizes Kuhnian ideas of scientific progress along four propositions, and explores Fleck's work in terms of analogies and differences with these propositions. I demonstrate that Fleck has provided us with a more sophisticated notion of normal progress, and, associated with it, a more sophisticated reading of incommensurability. In "Toward a Fleckian perspective on technological change and innovation", I survey Kuhn's influence in innovation studies, elaborate a number of advantages of a Fleckian perspective on innovation, and briefly discuss the phenomenon of configurational innovation. Against this background, the concluding section "Challenging incommensurability" develops a number of advantages of a Fleckian perspective on configurational innovation, both in terms of intracollective communication and intercollective communication.

\section{Kuhn and Fleck: A Comparison}

Ludwik Fleck's position as a seminal precursor of the contemporary understanding of science as a social process is well-established (see Latour 2008 for a recent and refreshing discussion). ${ }^{1}$ However, Fleck's legacy in technology studies and the study of technological change and innovation, in particular, is less pronounced, and

\footnotetext{
1 This is not the place to discuss Fleck's work and his legacy in contemporary science studies in full. Both his oeuvre as well as his role as a classic figure in science studies have been discussed elsewhere: The special issue in Studies in History and Philosophy of Biological and Biomedical Sciences introduced by Löwy (2004) is a good entrance point to the immediate discussion about Fleck's work, and Golinski
} 
has remained partial, largely mediated through Thomas Kuhn's work on scientific paradigms (see below). To shed light on associated pitfalls and missed opportunities, I compare Fleckian and Kuhnian ideas of scientific knowledge production in this section. I demonstrate that, while Kuhn has indeed resembled some of Fleck's central ideas, he was reluctant to accept Fleck's more radical claim that science is an essentially social process. To delve into this aspect, I start with a brief overview of Kuhn's main propositions and then explore a number of differences with Fleck's original conceptions.

\section{Thomas Kuhn on Scientific Paradigms}

Thomas Kuhn's book The Structure of Scientific Revolutions (SSR) has become one of the most widely received intellectual contributions to the social sciences. ${ }^{2}$ Indeed, Kuhn's attempt to do away with positivist, objectivist and universalist notions of science has engendered a prolific body of empirically based and historically sensitive ideas about scientific progress that have extensively been discussed elsewhere (Fuller 2003 for an overview and starting point). In what follows, I shall briefly recapitulate Kuhn's basic ideas along four propositions.

(I) Scientific knowledge production is fundamentally distinct from other forms of knowledge production. Indeed, Kuhn distinguishes between pre-paradigmatic science and paradigmatic science, where the emergence of a paradigm marks the transition to science proper (see Chapter 2 in SSR). Once a paradigm has emerged, knowledge production is not the same anymore. Those that adhere to the paradigm do not, in every step they take, have to rebuild the foundations of "their" field of study.

(II) Normal progress is Kuhn's term to describe scientific knowledge production that is guided by a paradigm (see Chapter 3 in SSR). Kuhn describes the essence of normal progress as "mopping-up activities"-expected solutions are developed to those problems that are already accepted as such. In this sense, normal progress allows for a directed, selective and in-depth exploration of a scientific field. First and foremost - and this is the true innovation of the paradigm concept (SSR: 187) paradigms are exemplary solutions that sketch out a pattern for problem solving; ${ }^{3}$ these exemplars, in turn, embody tacit norms, theories and rules that mark a constellation of group commitments. This interplay of concrete problem solutions, on the one hand, and group commitments, on the other, is at the center of a scientific paradigm and thus also of normal science.

\footnotetext{
Footnote 1 continued

(2005) as well as Smith (2005) provide excellent reviews of Fleck's influence in the various branches of science studies.

2 In what follows, I am referring to the second edition of the SSR that includes the important postscript (Kuhn 1970).

3 Kuhn's original book was heavily criticized for its plurivalent and fuzzy use of the term paradigm. Only in the famous postscript to the second edition of SSR, Kuhn attempted to rectify some of this confusion by distinguishing between paradigms as group commitments and paradigms as shared exemplars. He believed the latter to be the more useful and novel aspect of his work (SSR: 187).
} 
(III) Kuhn distinguishes between two forms of change-normal progress and paradigm shifts. In times of normal progress, a paradigm itself remains unaltered as a framework, while the knowledge produced according to that framework accumulates. Only after times of crises, when solutions discovered within a community do not fit with the expectations of a paradigm, a new paradigm may eventually overturn the existing one. A scientific revolution occurs. Kuhn's conception of scientific progress thus implies a distinction between paradigms as more or less constant entities, only altered in times of scientific revolutions, and the knowledge accumulated under the guidance of a paradigm.

(IV) Paradigms are shared by knowledge creating communities; normal science is a collective process. Kuhn himself, however, never fully appreciated the sociological implications of his work (Harwood 1986; Kuhn 1979), but addressed the issue of scientific communities mostly as an empirical problem about the reach of paradigms. The role scientific communities play for the process of problem solving itself has remained strikingly underdeveloped in Kuhn.

One aspect, however, has been clear for Kuhn—scientific paradigms are incommensurable. Notwithstanding its strict mathematical sense, Kuhn has used the notion of incommensurability in a fairly sociological way in SSR to denote that scientists belonging to different paradigms "practice their trades in different worlds" (SSR: 150); they are "always at least slightly at cross-purposes" (SSR: 148) and "bound partly to talk through each other" (SSR: 148). Proponents of different paradigms are thus constrained in their ability to interact in a meaningful way, and, in SSR, Kuhn suggests that disputes between paradigms can only be resolved at once, with one of the competing paradigms prevailing. For the Kuhn that wrote SSR, knowledge production across the boundaries between different paradigms is difficult, if not impossible, without leaving the realm of science. I shall call this a strong reading of incommensurability. Much of Kuhn's later work on incommensurability, most notably in Kuhn (1982), has shifted the focus toward a more analytical discussion of incommensurability between theories (not paradigms). As others have noted before, there are different versions of Kuhnian incommensurability (Hoyningen-Huene 1990; Oberheim 2005). In this paper, I confine myself to incommensurability in the sociologically and empirically sensitive way it was introduced in SSR (see also Babich 2003: 86n2, for this point). ${ }^{4}$ Below, we will see that this is also the way it has entered discussions about technological change and innovation.

\section{Ludwik Fleck on Thought Styles and Collectives}

In the preface to SSR, Kuhn mentions a 1935 monograph by Ludwik Fleck as an early influence that "anticipates many of my own ideas" (SSR: ix). At the time when Kuhn wrote SSR, Fleck's book was an almost unknown piece of work that gained wide attention, partly triggered by Kuhn's mentioning, only in the 1970s through the work of Baldamus and a translation into English as Genesis and

\footnotetext{
${ }^{4}$ Incommensurability, as suggested by Kuhn in SSR, is indeed an empirical statement rather than a nomological one (see Hacking 1983: 69).
} 
Development of a Scientific Fact (Fleck 1979, henceforth: GDSF). For Fleck, the key idea is that cognition not only involves the individual and some alleged reality, but, most importantly, the body of prior knowledge shared by a particular group of individuals. This body of shared knowledge mediates every instance of cognition and makes knowledge production an essentially social process. Hence, it is the thought collective, a group of individuals exchanging ideas and thus developing and nurturing a particular thought style (GDSF: 39), that is pivotal to cognition. Members of a thought collective struggle to align observations with their thought style to develop scientific "facts". Against this background, Fleck calls for a comparative epistemology (DGSF: 22) that would allow comparing different modes of knowledge production and different histories of ideas on equal terms. For him, every thought style is the product of a contingent historical process, where "the interaction between what is already known, what remains to be learned, and those who are to apprehend it" (DGSF: 38) leads to a certain constraint on thought (Denkzwang). Only through this intricate historical process, of which members of a thought collective are normally not aware, occurrences in a chaotic stream of observations appear as mere and simple facts, as "stylized signal[s] of resistance in thinking" (DGSF: 98).

While Fleck's work indeed bears important similarities with Kuhn's ideas, it is Fleck's radical conception of science as a social process that most clearly sets it apart from Kuhn. In what follows, I specify associated differences along the lines of the four propositions discussed above:

(I) According to Fleck, there is no fundamental difference between scientific and other forms of knowledge production. On the contrary, for Fleck, the particular strength of thought collective theory is revealed in its ability to compare very different forms of knowledge production (DGSF: 46-51). As such, scientific thinking is distinct only in style-by a "postulate "to maximize experience"" (DGSF: 51) and a typical orientation towards "maximum thought constraint with minimum thought caprice" (DGSF: 95). Hence, Fleck identifies a general pattern in the development of scientific facts, leading from a "vague initial visual perception" to the "developed direct visual perception of a form" (DGSF: 92); but this pattern is neither unique to scientific facts (although Fleck seems to suggest that it is more pronounced for them) nor does it distinguish between pre-science and science. This is an important difference with Kuhn's conception: paradigms seem to emerge at relatively distinct points in time, and once they are established, the modus operandi within the respective community becomes paradigmatic. In this sense, Kuhn suggests that the emergence of a paradigm is a form of social closure, separating two qualitatively different modes of collective inquiry. For Fleck, thought styles continuously change, and eventually they may exert the degree of thought constraint that characterizes scientific thinking.

(II) This implies a different conception of scientific progress by both authors. Indeed, in Fleck's work there is no elaborate equivalent to scientific

\footnotetext{
${ }^{5}$ Note that "perception of form" is the translation of "Gestaltsehen", a translation that masks Kuhn's and Fleck's joint emphasis on gestalt as an important element of paradigms and thought styles, respectively.
} 
revolutions. ${ }^{6}$ But also the very nature of cumulative scientific progress differs in the writings of Kuhn and Fleck. In normal science (Kuhn), the premises of a paradigm itself remain widely unaltered, only the knowledge that is produced under its guidance changes. For Fleck, there is no such distinction. A thought style changes with every instance of cognition, and truth is a network whose configuration continuously changes as new facts are developed (Smith 2000). Active and passive connections are the primary concepts Fleck uses to capture the nature of this continuous change, where active connections denote the collectively constructed preconditions of cognition, while passive connections refer to what is experienced as objective reality (DGSF: 40). Scientific thinking, according to Fleck, proceeds through increasing both active and passive connections (DGSF: 83, 94-95). This is similar to Kuhn's claim that scientific progress moves towards detail and depth rather than towards objective truth. Yet, there still is an essential difference: where Kuhn explains the tenacity of a paradigm through closure (what is accepted as a problem and expected as a solution, is established with the emergence of a paradigm), Fleck offers a more advanced explanation for the tenacity of a thought style-the continuous reproduction of the interlocking of active and passive linkages within the intricate network of scientists, experiments, publications, interests, organizations, and methods. Hence, constraint of thought (in a way, the equivalent to Kuhn's puzzle solving) is a result of continuous collective transformations to maintain and increase such constraint; facts are not just puzzles solved, but created actively in every instance of cognition. In other words, the "closedness" of thought styles is a matter of degree, a result of continuous efforts and object to change rather than absolute once accomplished, only surmountable through a paradigm shift.

A second difference exists because Fleck does not grant exemplary solutions the same epistemological status as Kuhn. Fleck does develop the notion of proto-ideas, i.e. early traces of concepts of contemporary thought styles, but these do not figure as central elements at the surface of recent versions of a thought style. In fact, protoideas are valuable because of their heuristic significance in the early phases of a thought collective, but as such, they are hardly able to demonstrate the functioning of a whole thought style (DGSF: 25)—which is the role Kuhn ascribes to exemplary artifacts within paradigms (SSR: 187-189).

(III) Most importantly, Fleck's and Kuhn's conceptions differ in their specifications of how a certain balance between stability and change is produced. In fact, Fleck dedicates wide sections of his monograph, particularly Chapter 4, to this issue. For him, a "thought collective exists whenever two or more persons are actually exchanging thought" (DGSF: 102). Of course, such rudimentary versions of a thought collective, while illustrating well the essence of the concept itself, are

\footnotetext{
${ }^{6}$ Fleck does suggest that the history of comprehensive theories proceeds through eras of classicity, "when only those facts are recognized that conform to it exactly", and eras with complications, "when exceptions begin to come forward" that may occasionally outnumber normal instances (DGSF: 29). While this anticipates some ideas that Kuhn uses to describe scientific revolutions, it is only a sideline argument of Fleck. This difference is the most obvious between the works of Kuhn and Fleck (see Babich 2003; Harwood 1986).
} 
volatile, "forming and dissolving at any moment" (DGSF: 13). They cannot account for the kind of intricate thinking that is characteristic of science. However, such initial groups may grow and persist over time and then the respective thought style "becomes fixed and formal in structure" (DGSF: 103). According to Fleck, modern science proceeds in such stable or comparatively stable thought collectives. With some simplification, therefore, Kuhn's paradigms resemble what Fleck has described as stable thought styles, but, in this sense, also represent an incomplete translation of Fleck's notion. For Fleck, it is an essential feature of thought styles that their degree of stability is subject to continuous social reproduction.

Stability and change of thought collectives is controlled by the communication of thought within and between collectives. For Fleck, thought collectives consist of intersecting circles, "a small esoteric circle and a larger exoteric circle" (DGSF: 105). The esoteric circle, where a thought style's coercive force is comparably weak (DGSF: 108), is the primary source of novelty, whereas the communication of thought between the inner and outer circles of a thought collective (intracollective communication) accounts for the tenacity of a thought style. What a difference with Kuhn's paradigms, which are esoteric circles by definition and produce novelty by accident rather than deliberately. But also the communication of thought between collectives (intercollective communication) constitutes an important source of novelty for Fleck (DGSF: 109): While he confines himself to relatively generic remarks in this regard, he is explicit about the effects of intercollective communication (DGSF: 109):

Just as the shared mood within a thought collective leads to an enhancement of thought currency, so does the change in mood during the intercollective passage of ideas produce an adjustment in this cash value across the entire range of possibilities, from a minor change in coloration, through an almost complete change of meaning, to the destruction of all sense (DGSF: 109-110).

Fleck indicates that intercollective communication is both a frequent occurrence and an important reason for change that ranges from minor adoptions to complete shifts in the foundations of a thought style. I shall call this a weak notion of incommensurability. ${ }^{7}$ In contrast to Kuhn, Fleck explicitly explored incommensurability as a fruitful tension from which a common ground may jointly be created. In the context of science, this challenging of incommensurability as a productive source of innovation has been thoroughly echoed, although not always with explicit reference to Fleck. ${ }^{8}$ The most notable examples are in the concepts of "boundary object" (Star and Griesemer 1989; Star 1993) and "trading zone" (Galison 1996) that have been devised to capture the interactions between scientific communities.

\footnotetext{
7 It is interesting that Fleck did use the notion of "incommensurability" himself (Fleck 1986), although not in his original monograph. While his elaboration of the term was sketchy, he did suggest that illnesses can only be understood in their completeness as a collection of changing and incommensurable ideas, "irrational in its entirety, [but] rational in its details" (Fleck 1986: 43).

${ }^{8}$ I am grateful to one anonymous reviewer for directing my attention to the need to make the connections between Fleck's intercollective communication and more recent concepts in STS explicit. A further discussion of intercollective communication in a narrower Fleckian sense can be found in Löwy (1988), Sinding (2004) and Fehr (2005).
} 
In the context of technological change and innovation, a comparably systematic treatment of the zones and spaces in which different knowledge communities might come together is thus far absent. I shall return to this issue below.

\section{Toward a Fleckian Perspective on Technological Change and Innovation}

\section{Kuhn's Legacy in Innovation Studies}

The influence of Kuhn's ideas of paradigms and revolutions on innovation studies can roughly be grouped into three streams. The first stream, associated primarily with the sociology of technology, has been built on the assumption that technology, just as science, can be conceived as a knowledge system. Essentially, then, technological change is a process of knowledge production that follows structured patterns similar to those of science. In particular Johnston (1972), and later Granberg and Stankiewicz (1981), Laudan (1984) and Clark (1987), have explicitly referred to Kuhn in introducing the notion of technological paradigms:

[...] a technological paradigm is a set of guiding principles generally accepted by practitioners in a particular field of technology. [...] there are sets of beliefs and principles, including relevant scientific laws. Also subsumed within the paradigm, but not identical with it, are exemplars. These are models which demonstrate the functioning and the success of a paradigm. [...] Thirdly, there is the body of techniques, and experiences based on previous practice (Johnston 1972: 122).

Johnston's adoption of the Kuhnian prototype has been criticized for establishing analytical boundaries between technological dynamics and the social matrix in which it is embedded (Pinch and Bijker 1984; Bijker 1987). Indeed, Johnston's work bears deterministic undertones, as the sole focus is on engineers' mindsets that push artifacts along the trajectories described by their technological properties. This critique has somewhat downplayed Johnston's careful resemblance of Kuhn's subtle description of paradigms as guiding, not determining corridors of future change, but it brings out that Johnston has indeed limited his analysis of technological change to the work of technologists and engineers.

More interesting, in this regard, is another aspect of his adaptation-in fact an aspect still present in many contemporary attempts to conceptualize knowledge practices in technological change: In technological paradigms, technical objects fulfill an equivalent function to scientific exemplars in Kuhnian paradigms. They thus play a central role in structuring knowledge practices, and explanations of technological change have continued to revolve around the involvement with discrete technical objects. This is pronounced in Bijker's description of social closure, where artifacts turn into an obdurate manifestation of the complex struggle that has led to a dominant interpretation of meaning (1995: 282). But also in Bucciarelli's (2002) object worlds, in Vincenti's (1995) technical shaping of technology, in Constant's (1987) communities of practitioners or even in Callon's (1986) actor worlds, the question of how and where to locate the practices of 
technological change center on communities, open or closed to a lesser or greater extent, and "their" technology (Jorgensen and Sorensen 1999; Tuomi 2002). The point is not that these concepts closely follow Kuhn-in fact, their reference to Kuhn is often tenuous and built on a fairly critical reflection of Kuhnian thought-, but that Kuhn's legacy in many contemporary approaches reveals itself in a focus on more or less well-confined and discrete pieces of technology. It is this artifact centrism, inherent already in the prototype of scientific exemplars, that most pronouncedly characterizes Kuhn's legacy in innovation studies.

The second approach, which has probably contributed most to the wide and transdisciplinary popularity of the notion of technological paradigms (see Peine 2008), has been commenced by Dosi's attempt to put technological paradigms into an explicitly economic framework (Dosi 1982). Here, the general thread has been to use Kuhnian ideas to reconcile demand pull and technology push models of innovation. The search heuristics and routines of technologists are patterned (i.e. the basis of non-random search activities) and embed information from the demand side (Nelson and Winter 1977; Sahal 1985; Saviotti 1988). In this sense, Kuhnian ideas are at the very foundation of what has become known as evolutionary economics (von Tunzelmann et al. 2008). Also evolutionary economics have adopted Kuhnian ideas in a metaphorical sense, but, in contrast to their sociological and historical forerunners, they have pursued a significant degree of formalizing the Kuhnian notion of puzzle solving (van den Belt and Rip 1987). ${ }^{9}$ In this connection, evolutionary economics have carried on an even stronger sense of artifact centrism, where discrete artifacts are at the heart of structuring the industrial sectors in which they are embedded (Dosi 1997).

A third approach has used a loose reference to Kuhn to conceptualize the evolution of industrial sectors and its entanglement with the nature of the underlying technology. Referring back to the seminal work of Abernathy and Utterback (1978) on dominant designs, the study of industrial dynamics has distinguished between different forms of industry evolution in dependence of the degree of technological standardization. In particular, the emergence of a dominant design has been identified as a watershed event that demarcates forms of loose standardization from a generally accepted strong standardization of core design principles (Anderson and Tushman 1990; Tushman and Anderson 1986). Although this work has referred to Kuhn only in passing (and often also indirectly through Dosi's work on technological paradigms), the similarities between dominant designs and Kuhnian paradigms have been emphasized (Anderson and Tushman 1990; Utterback and Suarez 1993; Teece 1986). The main difference with work in evolutionary economics is that dominant designs have been explored in terms of the effects they have on the structure of industries. In line with Kuhnian ideas, dominant designs have been shown to consolidate industry structures and thus usher in eras of industry maturity (Utterback and Suarez 1993). But, also very much in the spirit of the Kuhnian prototype, studies on dominant designs have been struggling to

\footnotetext{
${ }^{9}$ In evolutionary economics, technological problems and its associated trade-offs tend to be seen as describing somewhat inevitable "natural" trajectories for further change, rather than the results of actions and interactions of technologists and other social groups (MacKenzie 1992; van den Belt and Rip 1987).
} 
conceptualize and operationalized different degrees of dominance and industry maturity (Murmann and Frenken 2006).

I have provided a more detailed account of Kuhn's legacy in various notions of technological paradigms elsewhere (Peine 2006, 2008). What this brief outline should demonstrate is that Kuhnian though, while often used in a metaphorical sense, has left a considerable mark on the study of technological change and innovation. In the following section, I shall briefly discuss a number of problems associated with artifact centrism, and prepare the ground for a Fleckian perspective that can help tackling these problems.

\section{Artifact Centrism and Advantages of a Fleckian Perspective}

Kuhn's influence in the study of technological change and innovation revolves around artifact centrism: ${ }^{10}$ Artifacts and discrete artifacts, in particular, operate as analytical markers of the social locale in which patterned forms of technological change proceed. And for good reason! The Kuhnian prototype, after all, offered students of technological change a compelling way to conceptualize the influence of design decisions on further corridors of progress-regardless of the extent to which these design decisions are conceptualized as manifestations of a broader social, cultural, economic or industrial matrix. Hence, Kuhn's notion of paradigms has been applied to explain closure and the patterns of cumulative change that emerge with it. Indeed, it is a strength of the artifact centrism in the approaches above that they have delved into the interplay of technical decisions and practices of knowledge production.

Fleck's work connects well with artifact centrism, as it would acknowledge the distinct role of specialists and their involvement with a technology as well-an analytical emphasis that some critics of Kuhnian thought seem to blur too easily (see Vincenti 1991). As I have argued above, however, granting technologists such a distinct analytical space is not without difficulties, for it bears the risk for explaining cumulative technological change solely in terms of technical problems. Kuhn's heritage, therefore, poses an analytical quandary, as it offers a vocabulary to grasp patterned forms of cumulative change, while at the same time it has tended to downplay the contingencies of innovation by masking the embedding of technology with its broader societal context. A fresh look at Fleck's sophisticated distinction between eso- and exoteric circles of thought collectives seems to be helpful in this regard. It would share with the approaches above the particular strength of granting technologists and their style of producing knowledge a special position in the innovation process. But it would be more careful to not exaggerate their influence but rather shed light on their specific position within the intricate interplay of central and peripheral circles of a thought collective.

This aspect of Fleck's work-whose fruitfulness in the analysis of technological change has sparingly been recognized before (Shrum 1984: 79; Bijker 1987: 186n4) — would not in itself break the mold of artifact centrism. The analytical

\footnotetext{
${ }^{10} \mathrm{I}$ am indebted to one anonymous reviewer for proposing this label for a central theme in my argumentation.
} 
scope of Fleck, however, is not limited to conceptualize separate trajectories of technological change. Where the artifact centrism following from Kuhn's influence has induced analytical boundaries around the change processes associated with certain pieces of technology (and we might speculate that Kuhn's particular way of presenting incommensurability has contributed to this), Fleck's concept of intercollective communication suggests ways to put precisely the interplay of distinct change processes center stage. It is this aspect of the Fleckian prototype, the combination of intra- and intercollective communication of thought in an overlapping structure of different thought collectives, that bears the potential to overcome the explanatory limitations of artifact centrism regarding some recent changes in the organization of contemporary innovation.

\section{On Configurational Innovation}

In recent years, the rising relevance of Information and Communication Technologies (ICTs) has led to a proliferation of technological fields in which artifacts embedded in different trajectories of change are fused (Peine 2009). Examples at hand are such disparate fields as Smart Homes, Tele Care and Tele Health Systems, Augmented Reality or Computer Supported Cooperative Work. In different shadings, such systems of technology have been described as

- complex, to highlight technological interdependence between components in technological systems (Murmann and Frenken 2006; Rosenkopf and Tushman 1998),

- modular, to underpin that interdependence on the component level also leads to more complex organizational structures in innovation (Baldwin and Clark 2000),

- configurational, to describe that innovation process increasingly cut across the knowledge bases of both diverse industrial sectors and the local practices of users (Fleck 1993, 1994).

In what follows, I focus on this last category of configurational technologies and show how they challenge the explanatory power of Kuhn's heritage in innovation studies. Configurational technologies represent an increasing trend for ICT-related innovative activities to be distributed over disperse technological, organizational and domestic contexts (Pollock and Williams 2010; Williams et al. 2005; Voss et al. 2010). Rather than being characterized by a well-specified technological identity, configurations are more or less unique implementations of technical systems that draw on a loosely defined set of components. In a Smart Home, for instance, ICTs facilitate the interoperability of household product and services, such as white goods, consumer electronics and building functions, to offer new functionalities. In TeleCare settings, a specific configuration of remote care services and monitoring devices is embedded in the homes and private lives of older persons. It is a peculiar aspect of such domains that "their" technology remains unspecified: a configuration obtains an identity only as local contingencies, such as the everyday practices of older persons, become configured with generally available technical knowledge. Innovation of configurational technologies thus cuts across a wide range of 
knowledge bases, including the technical knowledge of the components, the local practical knowledge of users, and the "configurational" knowledge of those facilitating implementation. This constellation challenges the conventional wisdom about the locales of innovation, as the evolution of configurations does not revolve around a clearly defined technological artifact (Fleck 2002). Innovation of configurational technologies is pluricentric, so to speak, involving a range of artifacts that often have a history independent of their inclusion into the configuration.

The dynamics of configurational technologies, therefore, are characterized by repeated implementations from a certain set of components. Over time, these dynamics stabilize as more experience accumulates about aspects such as the range of components from which configurations draw, the types of functionalities that can be offered by certain configurations, or the distribution of profits among the involved actors. Yet, this does not lead to the articulation of a dominant configuration, but rather to pluriform identities of various degrees of stability (Peine 2009). In the Smart Home field, for instance, different prototype houses exist, players have entered the field that are specialized in implementing Smart Home systems, and companies associated with the different components have explored new business models by offering their previously stand-alone solutions within the context of systemic solutions. In this constellation, experience is accumulated about what Smart Homes can offer to its users, how to implement them into different contexts, or how to profit from these implementations. Nonetheless, Smart Homes are unlikely to develop a coherent identity that would resemble the kind of closure implicit to the artifact centrism discussed above. Smart Homes remain inherently contingent upon the specific context for which they are configured. This sustained "openness", in different shadings, is a pivotal feature that characterizes innovation around configurational technologies (Williams et al. 2005).

Conceptual tools inspired by Kuhn and the artifact centrism they have given rise to in different branches of the innovation literature seem to be particularly ill-suited to deal with this phenomenon. They have focused the attention of researchers on knowledge generation within certain collectives, while ICT-induced innovation of configurational technologies successfully establishes connections between otherwise separate collectives. In innovation studies, the Kuhn-inspired approaches discussed above continue to be puzzled by the distributed locales of configurational innovation.

\section{Challenging Incommensurability}

I have shown that Kuhn's idea of scientific paradigms has widely been used as a metaphor to capture certain characteristics of technological change and innovation: Technological paradigms-or related concepts such as frames or dominant designs - have pointed to the punctuated nature of innovation processes, where closure, in different conceptual specifications, marks the emergence of patterned, cumulative change driven by communities of practitioners that tackle the problems associated with "their" technology. Incommensurability in a Kuhnian sense has received very little explicit attention by innovation scholars. I contend, though, that 
Kuhn's particular way of presenting it in SSR has contributed to the conception of cumulative technological change as a relatively concealed trajectory revolving around a well-defined object of technology. ${ }^{11}$

Configurational technologies, where innovation cuts across different spheres of knowledge production, challenge a strong interpretation of incommensurability. Quite likely, Kuhn's positioning of paradigms as entrenched and closed structures has contributed to a conceptual blind spot in innovation studies in this regard. Kuhn has provided innovation scholars with a powerful imagery to grasp innovation in terms of articulating better generally available solutions. This imagery, however, is misleading in the light of systemic solutions that draw on the local contingencies to which they are adapted. I posit that Fleck's concepts of thought styles and collectives provide a more suitable imagery to grasp the salient features of configurational innovation - an imagery that retains the strong aspects of Kuhninspired metaphors, while also expanding their explanatory power. I shall elaborate upon this along the lines of intracollective and intercollective communication.

\section{Intracollective Communication in Technological Change and Innovation}

For Fleck, an essential feature of knowledge generation is that it proceeds in overlapping eso- and exoteric circles of a collective. As such, the idea of thought collectives provides interesting cues to complement notions like technological paradigms. Most importantly, Fleck's concepts delve deeper into the varied internal structure of the locales that drive change. Like Kuhn's prototype, also Fleck's prototype allows for conceptualizing stable patterns of change within (more or less) coherent groups. Fleck's ideas comprise those of Kuhn in the sense that they also allow for adopting a vocabulary of closure and related cumulative change. In fact, Fleck's description of stable and mature thought collectives correspondents well to Kuhnian paradigms, so that a Fleckian perspective on technological change includes what has been described as technological paradigms, frames or dominant design. I believe that this is a crucial and hitherto underrated aspect. Innovation is both contingent and structured, and previous approaches, often in examination of Kuhn's legacy, have tended to emphasize either of these aspects (for this point, see Russell and Williams 2002). But technological progress neither exclusively thrives on solving technological problems, nor is it endlessly contingent. Fleck's rich description of the social production of stability and change through intracollective communication provides a middle ground, in this regard, which is sensitive to the pivotal role of materiality in a non-reductionist way. For him, new knowledge is produced in esoteric circles of specialists-so far: in accordance with Kuhn's legacy-but the degree to which the mindset of this circle influences change en large depends on its entanglement with various exoteric circles. Conceiving of technological communities and their involvement with a technology as a thought

\footnotetext{
11 The only explicit treatment of Kuhnian incommensurability in innovation studies known to me is Dew (2006). His discussion of "incommensurate technological paradigms" indeed resembles closely the strong incommensurability that Kuhn suggests in parts of his work.
} 
collective is thus a powerful perspective to capture the intricate entanglement of the inputs of technologists, policy makers, users, and other players in innovation.

For Fleck, closure is a matter of degree rather than a tipping point. Passive and active couplings play a pivotal role here, when scientists strive to maximize thought constraint-that what appears within a thought style as objective fact. Thought constraint, I believe, is a fruitful metaphor to capture the role of artifacts in technological thought collectives as pieces of knowledge about technological functionality that have been proven to work. Technological artifacts, just as in the perspectives inspired by Kuhn, would remain at the heart of technological communities. But their role within these communities would not parallel the exemplary solutions in a Kuhnian sense that lay down a well-defined agenda of problems to be solved. Rather, their functioning would correspond to that of proto-ideas in the Fleckian sense. That is, they contain a basis for further articulation to which different circles of a collective can relate. Jointly, then, these proto-ideas are further articulated through intracollective communication until they may obtain a degree of stability that makes them similar to Kuhn's exemplars (DGSF: 29). This is an aspect of Fleck's work developed by Oudshoorn (1994) in her "archaeology" of sex hormones: proto-ideas are a basis for further development; but they remain open for the inputs of a diverse set of specialisms. In that sense, artifacts in a Fleckian imagery constitute "boundary objects" (Star 1993) that facilitate heterogeneous problem solving and crystallize the knowledge inputs from diverse specialisms.

Such a reading of artifacts as proto-ideas that provide initial "signals of resistance" is particularly relevant for understanding how different degrees of closure are realized, perpetuated and (re-)opened. Artifacts, indeed, embark on their innovation journey as initial propositions from a circle of specialists, but then they meander among different sites where they incorporate and structure the inputs of various actors. In a Fleckian perspective, initial design propositions become re-defined, enriched and increasingly obdurate, as they are "communicated" within the overlapping circles of designers, users, marketing departments, policy makers, and others. This connects very well with the burgeoning literature in technology studies about the entanglement of use and design in innovation (for an overview, see Oudshoorn and Pinch 2008). This literature, often through employing the metaphor of a script (Akrich 1992; Akrich and Latour 1992), has focused on how the inputs of users and designers mutually condition each other as they are inscribed in technical objects. Much of this literature, however, has pursued micro-level case studies and is thus bounded to specific local contexts. An imagery of thought styles and collectives would add to this a diachronic dimension to enlighten how initial designs become re-defined, enriched and stable as they travel through different circles involved with their production and use. Substituting for and complementing the imagery of technological paradigms with an imagery of thought styles and collectives, to delve deeper into the heterogeneous structure of technological communities, may be a very fruitful "classical" underpinning of the emerging vocabulary of design-use relations (see Hyysalo 2009). 


\section{Intercollective Communication in Configurational Innovation}

What is said in the previous section is neither completely new in technology studies-although, I believe, it offers a refreshing look at some underdeveloped cues provided by Fleck about technological change-nor does it break the mold of artifact centrism, yet. The advantages of capturing the entrenched and collective processes of technological change in a Fleckian imagery become particularly compelling in the context of configurational innovation. Here, not only intracollective communication, but also intercollective communication is a salient feature. As elaborated above, configurations evolve in pluricentric fields that comprise a range of artifacts that are assembled into systems in the light of local contingencies. Artifact centrism is a conceptual limitation in this regard, and Fleck's description of intercollective communication and the associated weak reading of incommensurability provide interesting complements. For Fleck, incommensurability between thought collectives constitutes an obstacle, but one that not only can be overcome, but that is frequently overcome and, then, constitutes an important sources of novelty. A Fleckian imagery, therefore, readily addresses pluricentric situations that comprise various and overlapping thought collectives with different gravity centers and degrees of closure.

We should grasp configurational innovation in terms of overlapping thought collectives with various centers. Such a reading would be empirically sensitive to the diversity of locales in which different types of knowledge are generated. Most importantly, it would acknowledge the mature and stable thought collectives at the component level-configurations, after all, link existing artifacts into a system - and focus on their relations with emerging, initially volatile thought collectives at the level of the configurational field. This field level comprises test or research sites to implement certain versions of a configuration, new services specialized in "configuring", or the development of new strategies for the commercial roll-out of configurations. These aspects, however, add to already existing and, to a certain degree, entrenched practices at the component level. Knowledge about configurational technologies, therefore, initially accumulates in an unstable and volatile structure in which members of different thought collectives start exploring the emerging configurational field. Intercollective communication is an essential feature of this delicate structure, which evolves, stabilizes, and links up to the "participating" collectives, while closure is perpetually protracted. Fleck's rich description of the social structure of thought collectives in modern science provides a vocabulary to theorize this peculiar organizational form of innovation properly.

Again, the idea of proto-ideas seems to be most valuable. Specific configurations, regardless of their degree of stability, are ill-suited to fulfill the conceptual position of exemplary solutions in a Kuhnian sense. They do not represent a sufficiently generic definition of the technology. Conceiving of configurations as proto-ideas, susceptible to continuous re-definition and refinement, however, offers more productive conceptual inroads to the dynamics of configurational technologies. Their initial signals of resistance would mean different things in different thought collectives, but this would be a basis for a robust refinement rather than a definite 
obstacle. A Fleckian imagery would thus be conceptually and empirically sensitive to the different perspectives involved in configurational innovation, to the different communities contributing to its development, and to the social production of tenacity and change in the pluricentric configurational fields. No need for a conceptual equivalent of an exemplary solution. Rather, heterogeneity, pluricentricity, negotiated degrees of stability, sustained openness and related terms would populate the conceptual landscape. In this sense, a Fleckian imagery successfully breaks down the conceptual boundaries that the Kuhnian heritage has drawn around the innovation trajectories of specific artifacts.

In science studies, incommensurability has been challenged before-establishing Fleck on the map of innovation scholars thus also suggests tapping into the more "Fleckian" approaches in science studies. That is, to acknowledge that configurational innovation resembles some features of "interdisciplinarity". Exploring further such ideas as "boundary objects" (Star 1993) or "trading zones" (Galison 1996) in the context of technological change and innovation may thus greatly illuminate our understanding of configurational innovation, how different industrial sectors come to grips with joint innovation trajectories, and how they continuously incorporate the local knowledge of users into innovation. While this is beyond the scope of the present paper, it emphasizes that a Fleckian imagery grasps nicely a number of pivotal yet under-researched aspects of contemporary innovation that is driven by the pervasive spread of ICTs.

\section{Conclusions}

This paper has explored Ludwik Fleck's conceptual framework and its potential value for the analysis of technological change and innovation. For this purpose, it has examined a number of differences that exist with Kuhn's ideas about scientific progress that have been so influential in the study of innovation. Fleck's work, while widely regarded as a seminal precursor in science studies, has thus far only received scarce attention by students of technological change and innovation. This is particularly unfortunate because it has left a number of interesting conceptual avenues unexplored that this early scholar of collective knowledge production has developed. I have demonstrated that, in the context of studying innovation, Fleck's conceptualization of intracollective communication combines the well-known advantages of the Kuhnian legacy in notions like technological paradigms and normal technological progress with a more sophisticated description of the social production of stability and change. For Fleck, closure is not a tipping point, but rather gradual, sustained and established within an overlapping structure of eso- and exoteric circles of a though collective. Conceptualizing the thought collectives that drive innovation would thus carefully distinguish between the influences of such diverse actors as technologists, users, regulators, lobby groups, and so forth. In this regard, differentiating between eso- and exoteric circles and their respective contributions to innovation would be a particular strength in overcoming the limitations of both technological and social determinist accounts of technological change. 
The most compelling strengths of a Fleckian imagery in innovation studies, however, comes to the fore in the context of contemporary ICT-induced innovation. I have briefly elaborated upon the phenomenon of configurational innovation, where different trajectories of technological change are interwoven and evolve simultaneously. Fleck's graded notion of closure together with his weak idea of incommensurability allows for conceptualizing configurational innovation in terms of stable thought collectives of the component knowledge and emerging, yet initially fragile thought collectives that overarch them. As such, Fleck's thought collective theory provides a unique and truly sociological basis for the analysis of configurational innovation.

Should we, then, develop a truly Fleckian approach to understand contemporary innovation? After all, Fleck never meant his theory to be applied to the analysis of technological change; furthermore, the idea of intercollective communication is rather sketchily available in his original work. What I propose in this paper, therefore, is more modest. I have tried to flesh out how an imagery using Fleck's ideas such as thought collectives and proto-ideas fruitfully complements current approaches in innovation studies that draw on metaphors derived from Kuhn. Especially, Kuhn's rather vague and ambivalent reading of incommensurability in SSR has had some unfortunate following in the form of what I have denoted as artifact centrism. An imagery based on thought collective theory is able to overcome a number of associated limitations. Innovation scholars should thus integrate a thorough reading of Fleck, not as a contemporary approach, but as a seminal classic, into their repertoire. Above, I have discussed Fleck's work to some detail and that section provides an introduction to his work for those not yet familiar with it. Acknowledging Fleck's fruitful conceptual cues should also direct the attention of innovation scholars to Fleckian approaches in science studies that have challenged incommensurability. Exploring these approaches may very well be most fruitful in coming to grips with some salient features of configurational innovation.

Open Access This article is distributed under the terms of the Creative Commons Attribution Noncommercial License which permits any noncommercial use, distribution, and reproduction in any medium, provided the original author(s) and source are credited.

\section{References}

Abernathy, William J., and James M. Utterback. 1978. Patterns of industrial innovation. Technology Review 80: 41-47.

Akrich, Madeleine. 1992. The description of technical objects. In Shaping technology/building societystudies in sociotechnical change, eds. Wiebe E. Bijker, and John Law, 205-224. Cambridge: The MIT Press.

Akrich, Madeleine, and Bruno Latour. 1992. A summary of a convenient vocabulary for the semiotics of human and nonhuman assemblies. In Shaping technology/building society-studies in sociotechnical change, eds. Wiebe Bijker, and John Law, 259-264. Cambridge: The MIT Press.

Anderson, Philip, and Michael L. Tushman. 1990. Technological discontinuities and dominant designs: A cyclical model of technological change. Administrative Science Quarterly 35: 604-633.

Babich, Babette E. 2003. From Fleck's denkstil to Kuhn's paradigm-conceptual schemes and incommensurabilities. International Studies in the Philosophy of Science 17: 75-92. 
Baldwin, Carliss Y., and Kim B. Clark. 2000. Design rules-the power of modularity. Cambridge: MIT Press.

Bijker, Wiebe E. 1987. The social construction of bakelite: Toward a theory of invention. In The social construction of technological systems-new directions in the sociology and history of technology, eds. Wiebe E. Bijker, Thomas P. Hughes, and Trevor Pinch, 159-187. Cambridge: MIT Press.

Bijker, Wiebe E. 1995. Of bicycles, baekelite and bulbs: Towards a theory of sociotechnical change. Cambridge, MA: MIT Press.

Bucciarelli, Louis L. 2002. Between thought and object in engineering design. Design Studies 23: 219-231.

Callon, Michel. 1986. Some elements of a sociology of translation: Domestication of the scallops and the fishermen of Saint Brieuc bay. In Power, action and belief: A new sociology of knowledge?, eds. John Law, 196-233. London: Routledge and Kegan Paul.

Clark, Norman. 1987. Similarities and differences between scientific and technological paradigms. Futures 19: 26-42.

Constant, Edward W. 1987. The social locus of technological practice: Community, system, or organization. In The social construction of technological systems-new directions in the sociology and history of technology, eds. Wiebe E. Bijker, Thomas P. Hughes, and Trevor Pinch, 223-242. Cambridge, London: The MIT Press.

Dew, Nicholas. 2006. Incommensurate technological paradigms? Quarreling in the RFID industry. Industrial and Corporate Change 15: 785-810.

Dosi, Giovanni. 1982. Technological paradigms and technological trajectories. Research Policy 11: 147-162.

Dosi, Giovanni. 1997. Opportunities, incentives and the collective patterns of technological change. Economic Journal 107: 1530-1547.

Fehr, Johannes. 2005. 'Vielstimmigkeit und der wissenschaftliche Umgang damit-Ansätze zu einer Fleck'schen Philologie. In Tatsache-Denkstil-Kontroverse: Auseinandersetzungen mit Ludwik Fleck, ed. Rainer Egloff. Zürich: Collegium Helveticum.

Fleck, James. 1993. Configurations: Crystallizing contingency. International Journal of Human Factors in Manufacturing 3: 15-36.

Fleck, James. 1994. Learning by trying: The implementation of configurational technology. Research Policy 23: 637-652.

Fleck, James. 2002. The structure of technological evolutions: Linear models, configurations, and systems of development. Paper presented to the Nobel symposium on "Science and industry in the 20th century”, Stockholm, November 21-23 2002.

Fleck, Ludwik. 1979. Genesis and development of a scientific fact. Chicago: University of Chicago Press.

Fleck, Ludwik. 1986. Some specific way of the medical way of thinking [german original from 1927]. In Cognition and fact: Materials on Ludwik Fleck, eds. Robert S. Cohen, and Thomas Schnelle, 39-46. Dordrecht: D. Reidel.

Fuller, Steve. 2003. Thomas Kuhn-a philosphical history of our times. Chicago: University of Chicago Press.

Galison, Peter. 1996. Computer simulations and the trading zone. In The disunity of science-boundaries, contexts, and power, eds. Peter Galison, and David J. Stump, 118-157. Stanford: Stanford University Press.

Golinski, Jan. 2005. Making natural knowledge: Constructivism and the history of science. Chicago: University of Chicago Press.

Granberg, Anders, and Rikard Stankiewicz. 1981. The development of generic technologies - the cognitive aspects. In Technological and industrial policy in China and Europe, eds. Ove Grandstrand, and Jon Sigurdson, 196-224. Lund: Research Policy Institute.

Hacking, Ian. 1983. Representing and intervening. Cambridge: Cambridge University Press.

Harwood, Jonathan. 1986. Ludwik Fleck and the sociology of knowledge. Social Studies of Science 16: 173-187.

Hoyningen-Huene, Paul. 1990. Kuhn's conception of incommensurability. Studies in History and Philosophy of Science Part A 21: 481-492.

Hyysalo, Sampsa. 2009. Figuring technologies, users, and designers: Steps towards an adequate vocabulary for design-use relation. In Use of science and technology in business: Exploring the impact of using activity for systems, organizations, and people, eds. Frans Prenkert, Enrico Baraldi, Hakan Hakansson, and Alexandra Waluszewski, 291-313. Bingley: Emerald. 
Johnston, Ron D. 1972. The internal structure of technology. In The sociological review monograph 18the sociology of science, eds. Paul Halmos, and Martin Albrow, 117-130. Keele: J.H. Brookes Printers Limited.

Jorgensen, Ulrik, and Ole Henning Sorensen. 1999. Arenas of development—a space populated by actorworlds, artefacts and surprises. Technology Analysis \& Strategic Management 11: 409-429.

Kaplan, Sarah, and Mary Tripsas. 2008. Thinking about technology: Applying a cognitive lens to technical change. Research Policy 37: 790-805.

Kuhn, Thomas S. 1970. The structure of scientific revolutions. Chicago: University of Chicago Press.

Kuhn, Thomas S. 1979. Foreword. In Genesis and development of a scientific fact, ed. Ludwik Fleck, viixi. Chicago, London: The University of Chicago Press.

Kuhn, Thomas S. 1982. Commensurability, comparability, communicability. PSA: Proceedings of the Biennial Meeting of the Philosophy of Science Association 1982: 669-688.

Latour, Bruno. 2008. A textbook case revisited - knowledge as a mode of existence. In The handbook of science and technology studies, eds. Edward J. Hackett, Olga Amsterdamska, Michael Lynch, and Judy Wajcman, 83-112. Cambridge: The MIT Press.

Laudan, R. (ed.). 1984. The nature of technological knowledge: Are models of scientific change relevant. Dordrecht: D. Reidel.

Löwy, Ilana. 1988. Ludwik Fleck on the social construction of medical knowledge. Sociology of Health \& Illness 10: 133-155.

Löwy, Ilana. 2004. Introduction: Ludwik Fleck's epistemology of medicine and biomedical sciences. Studies in History and Philosophy of Biological and Biomedical Sciences 35: 437-445.

MacKenzie, Donald. 1992. Economic and sociological explanations of technical change. In Technological change and company strategies, eds. Rod Coombs, P. Saviotti, and V. Walsh, 25-48. London: Academic Press.

Murmann, Johann Peter, and Koen Frenken. 2006. Toward a systematic framework for research on dominant designs, technological innovations, and industrial change. Research Policy 35: 925-952.

Nelson, Richard R., and Sidney G. Winter. 1977. In search for a useful theory of innovation. Research Policy 6: 36-76.

Oberheim, Eric. 2005. On the historical origins of the contemporary notion of incommensurability: Paul Feyerabend's assault on conceptual conservativism. Studies in the History and Philosophy of Science A 36: 363-390.

Oudshoorn, Nelly. 1994. Beyond the natural body: An archaeology of sex hormones. London: Routledge.

Oudshoorn, Nelly, and Trevor Pinch. 2008. User-technology relationships: Some recent developments. In The handbook of science and technology studies, 3rd ed, eds. Edward J. Hackett, Olga Amsterdamska, Michael Lynch, and Judy Wajcman, 541-565. Cambridge: The MIT Press.

Peine, Alexander. 2006. Innovation und Paradigma-Epistemische Stile in Innovationsprozessen. Bielefeld: Transcript.

Peine, Alexander. 2008. Technological paradigms and complex technical systems-the case of smart homes. Research Policy 37: 508-529.

Peine, Alexander. 2009. Understanding the dynamics of technological configurations-a conceptual framework and the case of smart homes. Technological Forecasting and Social Change 76: 396-409.

Pinch, Trevor, and Wiebe E. Bijker. 1984. The social construction of facts and artefacts: Or how the sociology of science and the sociology of technology might benefit each other. Social Studies of Science 14: 399-441.

Pollock, Neil, and Robin Williams. 2010. E-infrastructures: How do we know and understand them? Strategic ethnography and the biography of artefacts. Computer Supported Cooperative Work (CSCW) 19: 521-556.

Rosenkopf, Lori, and Michael L. Tushman. 1998. The coevolution of community networks and technology: Lessons from the flight simulation industry. Industrial and Corporate Change 7: 311-346.

Russell, Stewart, and Robin Williams. 2002. Social shaping of technology: Frameworks, findings and implications for policy with glossary of social shaping concepts. In Shaping technology, guiding policy-concepts, spaces and tools, eds. Knut H. Sörensen, and Robin Williams, 37-133. Cheltenham: Edward Elgar.

Sahal, Devendra. 1985. Technological guideposts and innovation avenues. Research Policy 14: 61-85.

Saviotti, Pier Paolo. 1988. Information, variety and entropy in technoeconomic development. Research Policy 17: 89-103. 
Shrum, Wesley. 1984. Scientific specialities and technical systems. Social Studies of Science 14: 63-90.

Sinding, Christiane. 2004. The specificity of medical facts: The case of diabetology. Studies in History and Philosophy of Biological and Biomedical Sciences 35: 545-559.

Smith, Barbara Herrnstein. 2000. Netting truth. PMLA 115: 1089-1095.

Smith, Barbara Herrnstein. 2005. Scandalous knowledge. Edinburgh: Edinburgh University Press.

Star, Susan Leigh. 1993. Cooperation without consensus in scientific problem solving: Dynamics of closure in open systems. In CSCW-cooperation or conflict?, ed. Steve Easterbrook, 93-106. London: Springer.

Star, Susan Leigh, and James R. Griesemer. 1989. Institutional ecology, 'translations' and boundary objects: Amateurs and professionals in Berkeley's museum of vertebrate zoology, 1907-1939. Social Studies of Science 19: 387-420.

Teece, David J. 1986. Profiting from technological innovation: Implications for integration, collaboration, licensing and public policy. Research Policy 15: 285-305.

Tuomi, Illka. 2002. Networks of innovation: Change and meaning in the age of the internet. Oxford: Oxford University Press.

Tushman, Michael L., and Philip Anderson. 1986. Technological discontinuities and organizational environments. Administrative Science Quarterly 31: 439-485.

Utterback, James M., and Fernando F. Suarez. 1993. Innovation, competition, and industry structure. Research Policy 22: 1-21.

van den Belt, Henk, and Arie Rip. 1987. The Nelson-Winter-Dosi model and synthetic dye chemistry. In The social construction of technological systems, eds. Wiebe E. Bijker, Thomas P. Hughes, and Trevor Pinch, 135-158. Cambridge: MIT Press.

Vincenti, Walter G. 1991. The scope for social impact in engineering outcomes: A diagrammatic aid to analysis. Social Studies of Science 21: 761-767.

Vincenti, Walter G. 1995. The technical shaping of technology: Real-world constraints and technical logic in Edison's electrical lighting system. Social Studies of Science 25: 553-574.

von Tunzelmann, Nick, Franco Malerba, Paul Nightingale, and Stan Metcalfe. 2008. Technological paradigms: Past, present and future. Industrial and Corporate Change 17: 467-484.

Voss, Alex, Marzieh Asgari-Targhi, Rob Procter, and David Fergusson. 2010. Adoption of e-infrastructure services: Configurations of practice. Philosophical Transactions of the Royal Society A: Mathematical, Physical and Engineering Sciences 368: 4161-4176.

Williams, Robin, James Stewart, and Roger Slack. 2005. Social learning in technological innovation: Experimenting with information and communication technologies. Cheltenham: Edward Elgar. 